The Asia-Pacific Education Research

December 2006, 15(1), 183-206

\title{
REFLECTING ON MISCUES IN CONTENT AREA READINGS: A CASE OF TWO LEARNERS
}

\author{
Joahna S. Mante \\ De La Salle University-Manila, Philippines
}

This paper is a case study of two college freshman students who initially exhibited different reading and learning behaviors in class. Different content area texts (Chemistry, Economic, and Literature) were selected and three oral reading miscue analysis cycles were conducted. The two participants reflected upon select miscues during each Retrospective Miscue Analysis (RMA) session. Miscue readings and retellings indicated some difference between the readings of the three texts of various types, and RMA discussions showed increased knowledge about the reading process.

Kenneth Goodman (1967) defines reading as a "psycholinguistic guessing game" (in Wallace 1992, p. 40). This means a reader uses three language cuing systems to make sense of the printed page. He calls these systems the graphophonic, semantic, and the syntactic cues. For Goodman, if a reader wants to understand a written text, he/she must make use of the phonetic and visual features of the language, employ syntactic knowledge, and recognize word collocations. Furthermore, through his many studies, he discovered that a person who reads a text slightly above his current reading level for the first time would commit "miscues". He defines the term as "those unexpected responses which were neither random, capricious, nor evidence of laziness or carelessness" and as the "window on the reading process" (Martens 1997, p. 2) that allows one to analyze the strategies used by a reader as he/she uses them.

He calls this study of miscues the Reading Miscue Inventory (RMI). For the many who have adopted the procedure, they find it to be a new way of looking at deviations from the text-not as errors or mistakes, but more of the interplay of the three language 
systems. According to educators who have used RMI, analyzing miscue patterns within the context of the printed text allows the teachers to understand the cuing systems the reader consistently relies upon, and their effectiveness (Moore \& Brantingham, 2003). Moreover, as a procedure that adheres to the whole language approach of language learning, Miscue Analysis claims to be childcentered and considers reading to be related to the other macro skills of listening, speaking, and writing (Wallace, 1992).

Tatlonghari (2002) enumerates and describes the steps in the RMI procedure. First, the researcher chooses reading material which should be a step or two steps higher than the current grade level of the reader. It should be new and interesting to the reader. Also, it should be long enough to have an ample amount of miscues to be analyzed. Second, the reader orally reads the selection while the researcher observes and marks all the deviations from the text. Audio taping the session is encouraged. Third, the reader retells all the things he/she can remember from the text (See Appendix E for Tatlonghari's Retelling Format). After the session, the researcher codes and analyzes the miscues using the RMI Coding Sheet and grades the retelling using the Retelling Format.

Later, Yetta Goodman, Kenneth's co-developer of the RMI, extended the procedure to add a step where the reader takes note of his own miscues and later evaluates and reflects on the effects of these miscues on their comprehension (Flippo, p. 2001). After the oral reading and retelling session, a discussion session is held where the reader is led to identify his miscues while listening to his oral reading tape. This is followed by an interview aimed at eliciting analysis and reflection by the reader on the types and quality of his miscues. With this extension, the procedure is now called the Retrospective Miscue Analysis (RMA).

For more than 30 years, both RMI and RMA have been used to study readers from early grade school pupils (Martens, 1998, in Ebersole, 2005) to graduate school students (Theurer, 2002). They have been used with readers of various aptitudes and learning 
disabilities and situations (Ebersole, 2005; Martens, 1998; Moore \& Brantingham, 2003). Aside from these areas, many researchers have adapted and modified the two procedures to fit their research interest (Arnold, 1982; Moon, 1990, in Hall, 2002). For instance, Martens (1997) used repeated readings with a student named Matthew and focused on his word recognition and fluency. Davenport, Lauritzen and Smith (2002) used over-the-shoulder miscue analysis to study an effective reader named Matt. All these researchers claim that the procedures helped them understand and analyze the reading processes for each of their subjects.

Still, researchers who believe and do not believe in the RMI and the RMA both identify certain limitations of the procedure. Tatlonghari (2002) explains that the procedure may not be done by a novice or an untrained reading teacher, for it calls for a big amount of evaluation and judgment of a reader's performance. He also mentions that the RMI is time consuming because it is always done on an individual basis. Hempenstall (n.d.), who does not believe in the procedures, cites problems with the theoretical basis of the RMI and RMA (the whole language view of reading) and its relevance to reading development. He further argues that as an assessment tool, the procedures are unreliable. This is opposed by Valencia, Hiebert, and Afflebach (1994) who consider the RMI as a meaningful reading assessment tool.

Noting the flexibility of the RMA in identifying the reading strategies of varied types of learners, it is interesting to know how college students attempt to make sense of the different content area texts they are given in school.

In this paper, the subjects are two college freshman students who initially exhibited different reading and learning behaviors in class. Different content area texts (Chemistry, Economic, and Literature) are selected and three oral reading miscue analysis cycles are conducted. The two participants reflect upon select miscues during each RMA session. The study poses the following research questions: 
1. What kinds of miscues do the two learners make when they read content area texts encountered in school?

2. What reading behaviors do the learners use when they read content area texts?

3. Is there a relationship between text types and the pattern of miscues?

\section{METHOD}

The Participants

The two subjects in this study are two freshman Business and Accountancy students in a private university in Manila, Philippines. They are both taking up English 1 (a Reading into Writing course) with the researcher as their professor. Bong (pseudonym), from the observation of the teacher, is a participative and responsible student in the class. His grades fall between 85-90 at the start of this research. On the other hand, Allan (pseudonym) is a very shy and reluctant student. He would never answer a question by the teacher unless it is specifically addressed to him. During group work, he allows other members of his group to talk and plan and he only does whatever the others assigned to him. His grade range at the start of this study is between 75-80. Also, during reading activities in the class, Allan reads very fast and finishes ahead of the others, but his output is always be incomplete and lacking in substance. Bong, on the other hand, always takes his time to read the text given to them in class and produces good outputs.

The researcher also learned later that English is Bong's third language (after Ilokano and Tagalog) whereas it is Allan's second. Both joined co-curricular activities like journalism and speech classes when they were in high school to develop their writing and speaking skills in English. Outside school, both seldom apply their skills in English. In Bong's case, it only happens when foreigners talk to him to ask for directions, and in Allan's case, this occurs when he communicates with people through the Internet. These perceived differences between the two made the researcher choose them as the participants in this study. 
When the researcher requested them to be the subjects in this study after informing them what the research is all about on July 21, 2006, they gave their consent to join in this endeavor. On July 25 , the participants had their individual orientation and initial interview with the researcher, who aimed to familiarize them with the RMA procedure and to get some basic information about their reading beliefs, practices, and background.

\section{The Reading Materials}

Functioning as stimulus in this study, the selection of materials followed the guidelines set by Goodman and Burke (1972, in Tatlonghari, 2002). Among these guidelines are those that say that the materials should be new to the participants and within their instructional level; the set should have both fiction and non-fiction selections, and they should be interesting to the readers.

With the guidelines in mind, the researcher chose three subject areas that both participants would take in the second term of the current school year. These were Economics, Chemistry, and Literature. The Chemistry text came from Chapter 1 entitled The Air We Breathe (10-18) of the book Chemistry in Context: Applying Chemistry to Society (5th ed.) by Eubanks et al. (20xx). The Economics text came from Chapter 1 entitled The Scope and Method of Economics (8-15) of the book The Principles of Economics $\left(6^{\text {th }} \mathrm{ed}\right.$.) by Case and Fair $(20 \mathrm{xx})$. Both were the required textbooks for Chemistry and Economics classes at the students' university. The short story used in this study is entitled $A$ Dark Brown Dog by Stephen Crane, which was downloaded by the researcher from the Internet. This story is about the friendship that developed between a young boy and a dog.

Each selection was encoded double-spaced in a computer and four copies of each text were prepared on $8 \times 5$ sheets of bond paper: Two copies were for the researcher's markings of the miscues of each participant, and the other two copies were given to the participants so they could mark their own miscues. 
Aside from the reading materials, the researcher also prepared copies of the Miscue Analysis Form (MAF) in which the miscues were coded and categorized, and the Retelling Format (RF) for grading the three retellings of the participants.

The Actual Retrospective Miscue Analysis Sessions

The individual RMA sessions were conducted in the late afternoons and lasted for 50 to 60 minutes each. The sessions were twice a week, one session for the reading and the retelling and one for the RMA, except during the first week when they met thrice because of the addition of the initial interview. All sessions were audio taped.

In the first oral reading and retelling sessions, both students read the Chemistry text about the earth's atmosphere. The retelling of the same text followed it. After this session, the researcher listened to the tape and marked all the deviations from the original text, with focus on the graphophonic, semantic, and syntactic acceptability of each miscue. The MAF was used for this purpose. The researcher listened to the retelling of Allan and Bong afterwards. To identify the strengths and weaknesses of their first retelling, she used the RF. The following day, Allan and Bong had their first Retrospective Miscue Analysis session, during which the researcher showed them the results of the previous session through the MAF and the RF. The two also shared their insights and reflection on their first oral reading and retelling activity.

In the second oral reading and retelling session, both students read the Economics text about economic theories, policies, and models. The procedure followed during the first session was again done for this session and was followed four days later by the second RMA session.

The third and last oral reading and retelling session took place when both students read the story A Dark Brown Dog following the usual procedure. Here, the researcher tried to determine if there were changes in the participants' reading beliefs 
and other insights and realizations they might have after undergoing the entire RMA procedure. They were given simple tokens of appreciation by the researcher after the interview.

\section{RESULTS AND DISCUSSION}

The Initial Interview

The researcher interviewed the two subjects separately. In both cases, the researcher started the session by showing the subject the Reading Strategy Awareness Inventory, which they answered during the first week of the term in their English class. Both explained their answer to each of the nine sentence completion items in the instrument. From these answers and justifications, the researcher was able to identify some similarities and differences in the reading practices and beliefs of the participants. For instance, both admitted that the topic of a reading selection affects their motivation to read. They both resort to outside sources (dictionary and thesaurus) when they meet an unfamiliar word in the text. Bong even brings his pocket dictionary to school each day. Both would reread the sentence with the unfamiliar word and would try to see the connection of that word to the other words in the sentence. They also tap whatever prior knowledge they have that may be relevant to understanding the text at hand. While reading material, both adjust their pace depending on its difficulty.

The two use different strategies when they come across a confusing part of a text. According to Allan, he would keep on reading until the text is clarified at some point. Bong, on the other hand, would check to see if the ideas expressed are consistent with one another. He does this by constantly pausing to review the concepts presented in the material. They also differ in their view on identifying the important sentences in a chapter of a book. For Allan, all sentences are important, but for Bong, only those sentences that give important details or facts are important. Their post reading strategy also varies. Allan usually recalls the important ideas he has read mentally while Bong reviews by highlighting the important parts of the text and by preparing summaries. 
To gather more information about the participants' views on the reading process and their significant reading experiences, the researcher also administered the Burke Reading Interview Questionnaire during the first session.

According to Allan, he prefers reading novels to other materials. He considers a female classmate in high school as his example of a good reader because this person reads various types of books with comprehension. She even introduced him to the hobby of reading novels. As for his strategy in reading novels, he reads them slowly because he believes that all sentences must be read because they are important. During summer breaks, he can finish a $500+$ page book in two days. His favorite novels are those by Paolo Coello and John Grisham. At the time of the interview, he was reading his first novel by Judith Mc Naught. He also enjoys reading comic books and the encyclopedia but he does not enjoy reading textbooks. In fact, he reads his schoolbooks fast because he is only after the main idea. He finds Calculus the most difficult textbook to read because Math books do not interest him and he would rather rely on the Math teacher's lecture to understand a particular lesson.

Allan recalls that it was his mother who first taught him how to read at the age of three. She would post pictures of animals with their names and the alphabet on his bedroom wall, which they constantly reviewed together. At present, he considers himself an average reader who is contented with his reading skills. If he would give advice to a struggling reader, it would be to read simple and enjoyable novels like Harry Potter. To end the interview, he defines reading this way: "You will always learn something when you read."

Bong, on the other hand, enjoys reading newspapers and Reader's Digest which he tries to read regularly. His primary purpose in reading is to get information; that is why he also enjoys reading magazines and his textbooks. He describes himself as an average reader who would like to improve his word-attack skills.

He remembers his Grade 1 teacher and church elders as the people who taught him how to read. He recalls being read the 
various Gospel stories. He looks up to Krisha, a block mate, as a good example of a good reader because she can read fast with good comprehension. He would advise a struggling reader to read material from his field of interest in order to start developing his reading skills, or an "easy to read material like the Reader's Digest." Finally, he defines reading as "the ability to comprehend and understand a written text."

It is obvious that the two subjects have different reading intentions, beliefs, and interests. One sees reading as a recreatory activity; thereby choosing novels over the other types of reading materials and advising others to start developing a likeness for reading by reading a novel. Along this line, this person considers the ability to have a big reading appetite as a basis for becoming a good reader. From this person's definition of reading, one would get the idea that he views reading as a product-there's a result from every reading activity.

The other one looks at reading as a tool to obtain information. This may be related to his choice of the newspaper, Reader's Digests, and his textbooks as his usual reading materials. For him, a good reader is someone who reads with comprehension that is related to his definition of reading. It can be inferred that this subject views reading as a process-attempting to make sense of what one sees from the printed page.

In the following sections, I will discuss how the data from the cases answer the research questions posed in the study.

What kinds of miscues do the two learners make when they read content area texts encountered in school?

The first selection read by the subjects was a section in the first chapter of the Chemistry text which is about the composition of the air. It is composed of 1,377 words. Figure 1 shows the Miscue Analysis Form categorizing Allan's miscues. 


\begin{tabular}{|c|c|c|c|c|c|c|}
\hline \multirow{3}{*}{$\begin{array}{l}\text { Name } \\
\text { Script }\end{array}$} & \multicolumn{6}{|c|}{ MISCUE ANALYSIS FORM 1} \\
\hline & \multicolumn{2}{|c|}{ Allan (Chemistry text) } & \multicolumn{4}{|c|}{ Date July 26} \\
\hline & Miscue & Grapophonic & Semantic & Syntactic & Non-response & Corrections \\
\hline Present & Presents & $\checkmark$ & 0 & 0 & & $\checkmark$ \\
\hline Took & Look & $\checkmark$ & 0 & $\checkmark$ & & $\checkmark$ \\
\hline National & Natural & $\checkmark$ & 0 & $\checkmark$ & & $\checkmark$ \\
\hline \multicolumn{5}{|c|}{ No. of repetitions } & 2 & \\
\hline \multicolumn{5}{|c|}{ No. of reversals } & 5 & \\
\hline \multicolumn{5}{|c|}{ No. of regression and unsuccessful attempt to correct } & 1 & \\
\hline \multicolumn{5}{|c|}{ No. of acceptable miscues } & 3 & \\
\hline
\end{tabular}

\section{Figure 1. Allan's MAF for the Chemistry text}

From the figure, it can be seen that Allan committed only three miscues, all graphophonically acceptable, which were corrected by the reader. The following excerpt from his miscue analysis shows an example of this type of miscue.

An alternative way to represent the composition of the air is in terms of the molecules (self-corrects) present

and atoms present in the mixture.

From this limited data, it can be said that Allan did not show the ability to substitute words which are semantically acceptable as the original. That is most probably the reason why he had to correct these miscues.

Although this study focuses on the graphophonic, semantic, and syntactic miscues, it is good to mention that Allan committed 24 repetition miscues while reading the selection, the biggest number for a specific kind of miscue in any of the three texts. A sample of Allan's repetition miscues is this:

Text: The previous exercise addresses how much air you breathe, but not equally important topic of what you breathe and whether it might be harmful. 
Allan: The previous exercise addresses how much air you breathe, but not equally important topic of what you breathe and whether it might be harmful, harmful.

When asked why he repeated some words while reading the text during the first RMA conversation, Allan said most of them were made unconsciously, while some were done because he felt he did not pronounce the words correctly so he repeated them. An example he gave is when he repeated the word regenerate because he felt he read it as degenerate. He was advised by his researcherteacher not to be so concerned with correct pronunciation while reading the next texts aloud because the goal is to read the text with comprehension.

For his retelling, Allan was given 60 points for his recall of a number of specifics, two major concepts, and one generalization statement he was able to recount (See point breakdown in the Appendix). During the RMA session, the researcher called his attention to his error in calling "atmosphere" "oxygen". Allan said it might be because he was thinking of the word of "oxygen" all throughout the retelling session.

Bong, on the other hand, committed seven miscues. Figure 2 shows his Miscue Analysis Form.

\begin{tabular}{|c|c|c|c|c|c|c|}
\hline \multicolumn{7}{|c|}{ MISCUE ANALYSIS FORM 2} \\
\hline Name Bo & \multicolumn{2}{|c|}{ Bong (Chemistry text) } & \multicolumn{2}{|c|}{ Date July 26} & \multirow[b]{2}{*}{ Non-response } & \multirow[b]{2}{*}{ Corrections } \\
\hline Script & Miscue $\mathrm{Gr}$ & Grapophonic & Semantic & Syntactic & & \\
\hline On & Or & $\checkmark$ & 0 & 0 & & \\
\hline Man & Men & $\checkmark$ & $\checkmark$ & $\checkmark$ & & $\checkmark$ \\
\hline Regenerate & Generate & $\checkmark$ & $\checkmark$ & $\checkmark$ & & $\checkmark$ \\
\hline The & A & 0 & $\checkmark$ & $\checkmark$ & & \\
\hline Blood & Body & 0 & $\checkmark$ & $\checkmark$ & & \\
\hline Essential & Essentially & $\checkmark$ & $\checkmark$ & 0 & & \\
\hline Exhale & Inhale & $\checkmark$ & 0 & $\checkmark$ & & $\checkmark$ \\
\hline \multicolumn{3}{|c|}{ No. of repetitions } & \multicolumn{4}{|c|}{1} \\
\hline \multirow{2}{*}{\multicolumn{3}{|c|}{$\begin{array}{l}\text { No. of omissions } \\
\text { No. of acceptable miscues }\end{array}$}} & \multicolumn{4}{|c|}{1} \\
\hline & & & & & 8 & \\
\hline
\end{tabular}

Figure 2. Bong's MAF for the Chemistry text 
It is clearly seen from the figure that Bong has more semantically acceptable miscues, which means that although he deviated from the text, he still makes sense of the print he is processing. The same can be said about his miscues being syntactically and graphophonically acceptable. The following excerpt from his miscue analysis shows an example of a semantically, syntactically, and graphophonically acceptable miscue.

This improvement has occurred through a combination of government actions,

(self-corrects) generate

chemical ingenuity, and allowing the atmosphere to regenerate naturally.

For his retelling, Bong was given 65 points. He was able to recount more specifics than Allan, but they had the same number of major concept recalls and generalizations. He could have received a higher score if not for his error in calling "Hamlet" "Romeo and Juliet" and in misinterpreting the concept of mouth-to-mouth resuscitation. At the start of the first RMA session, Bong immediately said that he knew he made a very big mistake in calling Hamlet Romeo and Juliet. He reasoned out that he was trying to use his prior knowledge-in particular, about Juliet's family name, which he thought was "Hamlet". The researcher told him that it is "Capulet" he was talking about and not "Hamlet". It was at this point that Bong really laughed at his own mistake. He further said that reading a complete text aloud is something new to him, but that he would try to improve on his reading and retelling in the next sessions.

During the same RMA session, the researcher asked Bong if he did not notice that he read $a$ for the and body for blood. He said that he really did not notice these "errors" (his own word) maybe because he was reading too fast. The researcher told him not to use the word "errors" because these are not really mistakes. She used a particular sentence to show her point-when he read body for blood in the sentence Oxygen is absorbed into our blood via the lungs. The mere fact that he did not notice these deviations is an indication that it did not sound wrong at all when he read it that way. More importantly, it was stressed to him that as long as the meaning of the sentence is preserved, it is all right to substitute a 
word for another word in the text. The researcher then introduced to Bong the term for this type of deviation from the text-"miscues".

The second selection was an Economics text about Economic theories, models, and policies. It is composed of 2,801 words. Figure 3 presents Allan's Miscue Analysis Form for this text.

\begin{tabular}{|c|c|c|c|c|c|}
\hline \multicolumn{6}{|c|}{ MISCUE ANALYSIS FORM 3} \\
\hline \multicolumn{3}{|c|}{ Name Allan (Economics text) } & \multicolumn{3}{|c|}{ Date August 1} \\
\hline Script & Miscue & Grapophonic & Semantic & Syntactic Non-response & Corrections \\
\hline Helps & Help & $\checkmark$ & $\checkmark$ & $\checkmark$ & \\
\hline Economics & Economic & $\checkmark$ & $\checkmark$ & 0 & \\
\hline Analyst & Analysis & $\checkmark$ & $\checkmark$ & $\checkmark$ & \\
\hline Championship & Campaign & 0 & $\checkmark$ & $\checkmark$ & $\checkmark$ \\
\hline Almost & Most & $\checkmark$ & 0 & 0 & $\checkmark$ \\
\hline Because & Becomes & $\checkmark$ & 0 & $\checkmark$ & \\
\hline Is & In & $\checkmark$ & 0 & 0 & \\
\hline Each & Reach & $\checkmark$ & 0 & 0 & $\checkmark$ \\
\hline \multirow{3}{*}{\multicolumn{2}{|c|}{$\begin{array}{l}\text { No. of repetitions } \\
\text { No. of omissions } \\
\text { No. of reversals }\end{array}$}} & 18 & \multirow{3}{*}{\multicolumn{2}{|c|}{$\begin{array}{l}\text { No. of acceptable miscues } \\
\text { No. of insertions }\end{array}$}} & 7 \\
\hline & & 2 & & & 2 \\
\hline & & 5 & & & \\
\hline
\end{tabular}

Figure 3. Allan's MAF for the Economics text

The figure shows a general improvement in Allan's oral reading of the text. Eighty-eight percent of his miscues are graphophonically acceptable and $50 \%$ are syntactically acceptable. It should be noted that in this second oral reading, Allan has allowed most miscues that are semantically acceptable to remain uncorrected. This is a good sign that he is focusing on attempting to make sense of the text. To support this interpretation, he also corrected two semantically unacceptable miscues. That is why there is an increase in the number of his acceptable miscues. Vacca, Vacca and Gove (2002, in Moore \& Brantingham, 2003) proposed a formula in which self-corrected miscues are added to the semantically acceptable miscues to come up with the total acceptable miscues. This determines the effectivity of the substitution. A decrease in his repetition miscues is also evident, but there are still a number of reversal miscues in this session. 
For his retelling, Allan showed a slight improvement in his recalling of specifics. He was able to define terms like economic policy, variable, theories, and models. Also, he explained the difference between a 2D and a 3D map and the scientists who proposed different theories about the solar system. But there were still some specifics and major concepts that were not mentioned by Allan. Lastly, there was no attempt to generalize during the retelling. Based on these findings, the researcher gave Allan 50 points, 10 points lower than the previous retelling.

The RMA session for the Economic text revolved around the discussion on why Allan recalled very few details and concepts during the retelling of the text. He said that he found the text difficult and uninteresting, which was the reason why he failed to mention a good amount of information during the retelling period. Also, unlike the first text about the atmosphere, the topic in the second selection is new to him, preventing him from recalling more details and concepts. The researcher asked whether the length of the material affected his ability to recall, but he said that while the second text was longer than the first one, it was the topic that really affected his inability to recall.

Bong had the same number of major miscues. Figure 4 presents his Miscue Analysis Form.

\begin{tabular}{|c|c|c|c|c|c|}
\hline & & MISCUE AI & NALYSIS & FORM 4 & \\
\hline Name Bon & (Economic & ics text) & & Date August 1 & \\
\hline Script & Miscue & Grapophonic & Semantic & Syntactic Non-res & Corrections \\
\hline And & Of & 0 & 0 & 0 & \\
\hline Employment & Employers & $\checkmark$ & 0 & $\checkmark$ & $\checkmark$ \\
\hline Thousands & Thorough & 0 & 0 & 0 & $\checkmark$ \\
\hline Come & Comes & $\checkmark$ & $\checkmark$ & $\checkmark$ & $\checkmark$ \\
\hline Colors & Color & $\checkmark$ & $\checkmark$ & $\checkmark$ & $\checkmark$ \\
\hline Helps & Help & $\checkmark$ & $\checkmark$ & $\checkmark$ & \\
\hline Singles & Single & $\checkmark$ & $\checkmark$ & $\checkmark$ & \\
\hline Date & Data & $\checkmark$ & 0 & $\checkmark$ & \\
\hline No. of repetiti & & 2 & No. of $a$ & acceptable miscues & 8 \\
\hline No. of omissi & & 1 & No. of in & nsertions & 2 \\
\hline
\end{tabular}

Figure 4. Bong's MAF for the Economics text 
The figure reveals that $75 \%$ of his miscues are both syntactically and graphophonically acceptable. As far as semantic acceptability is concerned, Bong exhibited a slightly better performance than Allan because he had one more acceptable miscue. Just like Allan, he allowed semantically acceptable miscues to remain uncorrected. He repeated a word only twice; omitted a word once, and inserted a word (an article) twice.

For his retelling, Bong was given 65 points, similar to what was given to him during the first retelling. He was able to recall more specifics than Allan, and more importantly, showed the ability to explain the connection among these specifics. For example, he explained the difference between a variable and a constant, which was not made explicit in the text. But, like in the first retelling, Bong made some errors. He said that "Ockham's razor" got its name from a scientist, but it is actually named after a place. He also misconstrued the concept of "post hoc".

During the RMA session, Bong said that he was more relaxed when he read the second selection and he was less conscious about his pronunciation of the words. According to him, pausing after reading the text just before starting the retelling helped him gather his thoughts first. He attributed his errors during the retelling to the considerable amount of information he had to recall.

Also, during this RMA session, the researcher involved Allan and Bong in identifying and marking some of the miscues they committed. Through this, they were able to realize that they were not aware when some of the miscues happened. They also noticed that although they made more miscues in the second text, most of these did not really change the meaning of the selection.

The third selection was a short story written by Stephen Crane entitled A Dark Brown Dog. It is a short about how a young boy and a dog developed a friendship. It has 2,344 words. Figure 5 shows Allan's Miscue Analysis Form for this text. 


\begin{tabular}{|llcccc|}
\hline \multicolumn{5}{c}{ MISCUE ANALYSIS FORM 5 } \\
Name Allan (Lit text) & \multicolumn{5}{c|}{ Date August 8 } \\
Script & Miscue & Grapophonic & Semantic Syntactic Non-response Corrections \\
& & & & $\checkmark$ & \\
Beat & Beating & $\checkmark$ & $\checkmark$ & 0 & $\checkmark$ \\
To & So & $\checkmark$ & 0 & $\checkmark$ & \\
Matters & Manners & $\checkmark$ & 0 & $\checkmark$ & \\
Industriously & Industrially & $\checkmark$ & 0 & 0 & \\
Charge & Child & 0 & 0 & 0 & \\
In & Is & $\checkmark$ & $\checkmark$ & 0 & \\
Furthermore & Therefore & 0 & $\checkmark$ & $\checkmark$ & \\
Friend & Friends & $\checkmark$ & $\checkmark$ & $\checkmark$ & \\
Alleyway & Alley & $\checkmark$ & $\checkmark$ & $\checkmark$ & \\
& & & & & \\
No. of repetitions & 13 & No. of acceptable miscues & 8 \\
No. of omissions & 1 & No. of insertions & \\
\hline
\end{tabular}

Figure 5. Allan's MAF for the Literature text

Allan continued to do well with graphophonically acceptable miscues. It can also be noticed that in two of the three occurrences when a miscue is acceptable in the three aspects (graphophonic, semantic, and syntactic), Allan did not bother to correct the miscue. That is a sign of a good reader who is able to substitute words while still keeping the meaning of the text. The high number of his acceptable miscues reveals his general understanding of the story. His repetition miscues continued to drop.

The score he received for the retelling supports these findings. Allan received 75 points for his third retelling, the highest among the three sessions that he had, and higher than Bong's score. In his retelling he mentioned both the major and the minor characters of the story. He also narrated the story in the order following its plot, and no important event was omitted. The things missing, on the other hand, were the theme and information about the character development as the plot evolves.

During the RMA session, Allan said that he had the easiest time in retelling the third selection because it was a story. He also said that the miscues he committed while reading the story did not 
affect his retelling. Lastly, he revealed that he enjoyed reading the story as compared to the uninteresting first text and the difficult second selection. In this session, the researcher and the participants compared their coded miscues, which revealed very similar interpretation and judgment.

Interesting findings are revealed in Bong's Miscue Analysis Form for Literature found in Figure 6.

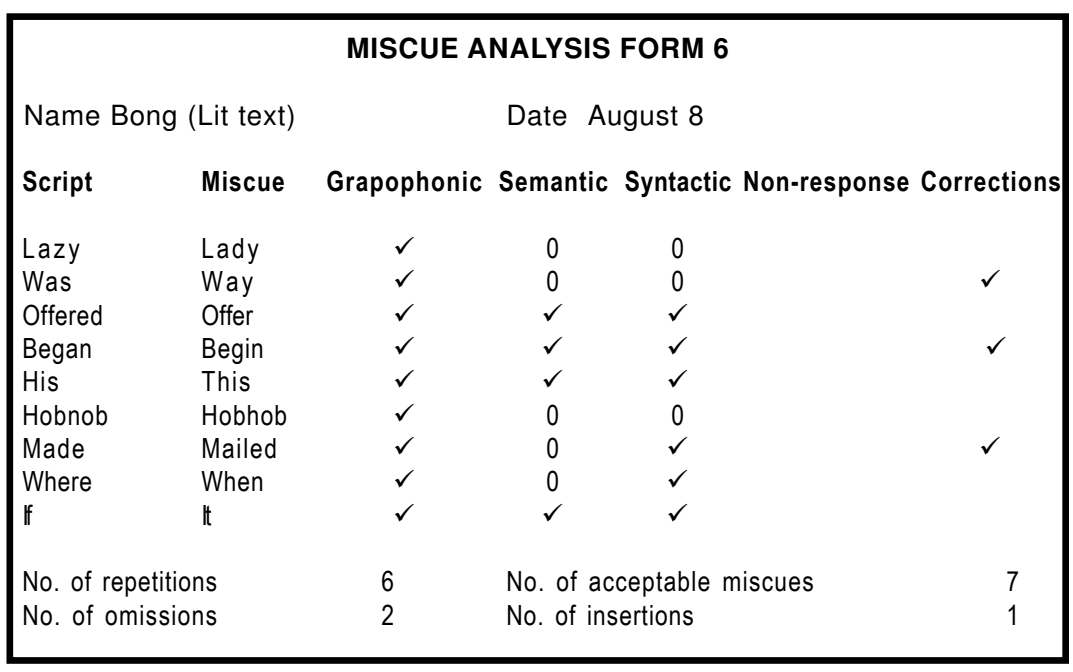

\section{Figure 6. Bong's MAF for the Literature text}

From the figure, one can see Bong consistently scored high as far as acceptable miscues are concerned. It can also be noticed that, like Allan, in instances when a miscue is acceptable in the three aspects (graphophonic, semantic, and syntactic), Bong did not bother to correct the miscue. Again, this is a sign of a good reader. He also committed six repetitions while reading the text, his highest among the three reading sessions.

For his retelling, Bong was given 65 points. Although he was able to recall the major events in order, he missed on some of the minor ones. Like Allan, he gave no information about character development and the theme of the story. 
During the RMA session, Bong felt he did a good job in retelling the story. In his view, he was able to recall all the important parts of the story. When told that he did not mention anything about the theme, Bong said, "It's about friendship." He noticed that he was no longer conscious about his miscues, especially those that concern pronunciation, which was his major concern at the start. According to him, he now considered it okay to deviate from the text, as long as the meaning was preserved.

From the three oral reading sessions involving three content area materials, it can be said that the two participants gradually realized the purpose of the study and the help it could possibly offer to them. At the start, since the process is new to them, both readers made a very small number of miscues, most of which were graphophonic miscues that, more often than not, were corrected. This is consistent with the findings of a previous research that claims that for a beginner, "low miscue analysis scores on the first reading reflect the difficulty he was having" (Martens, 1997, p. 9). As they went on with the process, they made more miscues, which research interprets to mean that they are getting used to the procedure (Martens, 1997). As they made more acceptable miscues, the two also made fewer corrections since they both discovered in the RMA sessions that not all miscues need to be corrected.

What reading behaviors do the learners exhibit when they read content area texts?

At the start of the RMA process, it was clearly seen that the two participants were reading close to the printed text. Most of the graphophonic miscues were corrected because as the two revealed separately during the initial interview that every sentence in a text is important and that a good reader needs a wide vocabulary. At certain instances, the two participants also used their prior knowledge to understand the text. Bong used his prior knowledge on physical and chemical reactions, while Allan tapped his knowledge about the gas argon. These approaches, the researcher believes, affected their manner of reading the first selection and the kind of miscues they made. 
As the process continued, the two became more relaxed with the procedure and started exhibiting more meaningful miscues. They began ignoring those miscues that do not change the meaning of the text. They also started inferring based on the information given in the text. This does not mean, however, that their inferences were all correct. Bong, for example, wrongly inferred to the concept of "post hoc" based on an example given in the text. Allan, on the other hand, was able to infer what the concept of "rent control" is, based on the situation given in the selection.

When they were reading the last text, the two focused on meaning-making reading behaviors. It was only in the third selection that both Allan and Bong did not pause at any point while reading the text aloud. Both reasoned during the RMA session that they did want to break the flow of the story by pausing. This gave the researcher the idea that both were enjoying reading the story, which was why they did not want to pause. Also, neither complained that the story was long or uninteresting. When they did the retelling, both were able to follow the original plot of the story, and supplied their retelling with many meaningful details-something they did not do in the previous retellings.

The researcher believes that this may also mean that the two used their imagination while reading in order to picture how the characters looked and acted at various points in the story. This made retelling the story an easy task for them. Extending this theory, it can be claimed that the two were also using their prior knowledge while reading and retelling the story. Bong said that the dog in the story is a homeless dog, but there was no explicit mention of anything to that effect. But since the boy and the dog met on the street, he probably assumed that no one owned the dog — not a bad guess at all.

All the reading behaviors reported in this research confirm the findings of earlier studies that various behaviors and strategies are used at certain points in the RMA that show the development of the readers undergoing the process (Theurer, 2002; Martens, 1997). 
Is there a relationship between text types and the pattern of miscues?

The first two texts are expository in nature. The Chemistry text uses the classification pattern to discuss the major components of the air, while the Economics text uses the enumeration/list pattern to discuss the various concepts used in explaining economic theories, policies, and models. The third selection is of the narrative type.

Looking at the miscues committed while two participants were reading the three different texts, the researcher observed two particular patterns formed between a particular text and a particular kind of miscue. One noticeable pattern is that the participants committed more miscues (graphophonic, semantic, and syntactic combined) when they read the Literature text that followed the narrative pattern. Bong and Allan's combined miscues for this selection is 37, while they only had 20 in the Chemistry text and 31 in the Economics text-both follow the expository pattern. This finding runs parallel with a previous finding made. In Ebersole (2005), findings reveal that "the literature reading had a higher number of miscues per hundred words (MPHW)...than in the math and science text" (p. 6).

The second pattern shows that there are more acceptable miscues for the two participants for the Literature text. Allan and Bong had combined acceptable miscues of 15 for the said narrative pattern, while they had an average combined acceptable miscues score of 13 , though this is only a very slight difference. In a previous research by Moore and Brantingham (2003), they explained that acceptable miscues made by a reader are related to his or her ability to construct meaning. It can be stated, therefore, that among the three texts, the participants best understood the one that follows the narrative pattern. It can be argued though that it may be the sequence of the texts that affected the number of acceptable miscues (the Literature text was given last among the three, at a point when the participants were more relaxed compared to when they read the other two selections) and not the text type. 


\section{Conclusions and Recommendations}

Although this paper reports a case study of only two learners, it was able to confirm the findings set by previous research on the soundness of the Retrospective Miscue Analysis as a tool in identifying and analyzing the reading processes and behaviors employed by learners as they attempt to give meaning to printed texts. In this study, Allan, who initially thought that every sentence in selection should be read because it is important, began his first oral reading session by focusing on the proper pronunciation of the words. This allowed to him to produce fewer miscues, a low level at that, because he focused on sounding out the words and not on understanding the text. As the procedure continued, he began committing high-level and acceptable miscues because he realized that it is acceptable to substitute a word in a text as long as the original meaning is preserved.

Bong, the other participant, can be described as a "reluctant good reader" because he committed a good number of acceptable miscues even at the start of the procedure, but he initially thought he was committing errors in reading. He worked on his confidence and empowerment as a reader as he continued from one session to the next. During the final interview, he told the researcher that he became a more confident reader after the sessions because he realized that miscues are not similar to errors.

From the few instances of miscues committed in reading the expository materials, it can also be concluded that students did not focus on trying to comprehend these texts, but rather "read close to the text" (Martens, p. 9), which means that the participants' attention was on the printed page and they were not really attempting to make sense of what they are reading. The results of the retelling for these materials also supports this conclusion.

It is therefore recommended that teachers teach text structure explicitly, so that students will learn how ideas and information are arranged in these kinds of materials. Research reveals that expository texts in general are more difficult to 
comprehend, especially because they come in various structures that students are not familiar with (Williams, 2005). Furthermore, the study made by Pearson and Duke (n.d.) identified a relationship between awareness of expository text structure and positive reading comprehension.

Another recommendation involves the choice of textbooks. There is a need to study whether the books schools ask the students to read are well-written in terms of content, organization, identification of main ideas, and difference between relevant and irrelevant information. In America, a study revealed that some history textbooks "did not make obvious the major concepts of history" (White, cited in Kinder \& Bursuck, 1991, and in Dickson, Simmons, \& Kameenui, n.d., par.3) among many other negative findings. Similar reports were made about science textbooks (Scruggs \& Mastropieri, 1993, in Dickson, Simmons, \& Kameenui, n.d.). Together with the explicit teaching of expository text comprehension, having well-written textbooks will help students understand various content area readings.

Still another recommendation is that more authentic assessment tools in reading like the RMA be used to accurately and reliably identify the strengths and weaknesses of readers of various abilities and levels. Furthermore, it is suggested that more studies on the use of the RMA procedure with college students who read content area materials be made, since this researcher did not see a random search of this type of research when she was looking for related literature for this paper.

Undertaking this research also gave the researcher/teacher some interesting insights relevant to the teaching and learning process. First, this attempt to use the RMA empowered both the teacher and the readers. On one hand, the two readers were free to give meaning to the text they were reading and to identify deviations from the text as either "errors" or "miscues". Of course, this freedom was not absolute, for the readers needed to justify the decisions they made. On the other hand, the teacher was empowered to assess the strength and weaknesses of the readers' performance 
by relying on her own judgment and the involvement of the readers themselves. Together with the readers, the teacher determined whether a deviation is meaningful or unacceptable. Second, the procedure enabled the teacher to reflect on her methods in teaching reading. Questions like "How much time do I spend in teaching meaning making to my students?" and "How do I stress to my students the importance of having strategies when they read their content area textbooks?" were pondered upon. Third, RMA allowed the teacher to connect with the readers on a more individual and personal level, which made the evaluation of their reading tasks more accurate. During the retelling and the RMA interviews, both the teacher and the student clarified important points in the procedure, which is difficult to do in the typical classroom set up. Finally, as the "window on the reading process", RMA is now seen by the researcher to be an invitation to teachers to use a more qualitative, authentic, and student-involved tool to identify good readers and to help reluctant and poor readers.

\section{References}

Davenport, M.R., Lauritzen, C., \& Smith, K. (2002). Inviting reflection on reading through over the shoulder miscue analysis. Language Arts, 80(2), 109-118. Retrieved August 14, 2006 from http:// proquest.umi.com/pqd web.

Dickson, S., Simmons, D., \& Kameenui, E. (n.d). Text organization and its relation to reading comprehension: A synthesis of the research. National Center to Improve the Tools of Educators, funded by the U.S. Office of Special Education Programs. Retrieved August 17, 2006, from http://www.uoregon.edu.

Ebersole, M. (2005) Reflecting on miscues in content area readings. Academic Exchange Quarterly, 9(2),1-9.

Flippo, R. (Ed). (2001). Researchers in search of common ground. Delaware: International Reading Association.

Hall, K. (2002). Listening to Stephen read. Buckingham: Open University Press.

Hempenstall, K. (n.d.). Miscue analysis: A critique. Retrieved August 14, 2006, from http://www.educationnews.org/ Curriculum/Reading/Miscue_Analysis_A_Critque.htm 
Martens, P. (1997). What miscue reveals about word recognition and repeated reading: A view through the "miscue window". Language Arts, 74(8), 600-609.

Martens, P. (1998). Using retrospective miscue analysis to inquire: Learning from Michael. The Reading Teacher, 52(2),176-180.

Moore, A. \& Brantingham, K. (2003). Nathan: A case study in reader response and retrospective miscue analysis. The Reading Teacher, 56(5), 466-474.

Moore, R., \& Aspergen, C. (2001) Reflective conversations between two learners: Retrospective miscue analysis. Journal of Adolescent \& Adult Literacy, 44(6), 492-503.

Pearson, N. \& Duke, P. D. (n.d.). Effective practices for developing reading comprehension. Retrieved August 17, 2006, from http:/ /www.itrc.ucf.edu/forpd/strategies/strattextstructure.html.

Tatlonghari, M. (2002). Using the miscue reading inventory. The RAP Journal, 25, 33-39.

Theurer, J. (2002). The power of retrospective miscue analysis: One pre-service teacher's journey as she considers the reading process. The Reading Matrix, 2(1), 1-23.

Valencia, S., Hiebert, E., \& Afflerbach, P. (Eds) (1994). Authenthic reading assessment: Practices and possibilities. Delaware: International Reading Association.

Wallace, C. (1992). Reading. Oxford University Press.

Williams, J. P. (2005). Instruction in reading comprehension for primary-grade students: A focus on text structure. Retrieved August 17, 2006, from http://www.itrc.ucf.edu/forpd/strategies/ strattextstructure.html). 